\title{
PENGENALAN APLIKASI ROBOMIND KEPADA SANTRIWAN/SANTRIWATI DI PONDOK PESANTREN AL MUNAWARRAH
}

\author{
${ }^{1)}$ Wita Yulianti, ${ }^{2}$ Salamun \\ ${ }^{[1,2]}$ Program Studi Teknik Informatika, Fakultas Teknik, Universitas Abdurrab \\ ${ }^{[1,2]}$ Jl. Riau Ujung No.73 Payung Sekaki, Pekanbaru - Riau - Indonesia \\ E-Mail : wita.yulianti@univrab.ac.id
}

\begin{abstract}
ABSTRAK
Robomind merupakan software gratis yang dapat mempelajari simulasi sistem kecerdasan buatan seperti robot. Software Robomind diciptakan sebagai pembelajaran di bidang teknologi robot. Dengan Robomind ini dapat dipelajari teknik pemrograman dasar dalam mengetahui proses bekerja sebuah robot. Software Robomind dapat digunakan di dunia pendidikan sebagai pembelajaran bagi pemula mengenai simulasi robot untuk siswa-siswi SMP dan SMA atau sederajatnya. Dalam menghadapi revolusi indutri 4.0 perkembangan teknologi akan terus berkembang, maka kehidupan yang sudah berteknologi ini tidak dapat dipungkuri untuk menolak. Agar siswasiswa ini dapat menghadapi perkembangan teknologi yang telah memasuki revolusi industri 4.0, harus dapat mengetahui teknologi dengan mempelajari dan memahami perkembangannya setiap pembaharuan. Salah satu perkembangan teknologi di bidang ilmu Artificial Inteligence atau kecerdasan buatan. Software Robomind ini diterapkan dalam proses belajar ke siswa-siswi dalam bentuk workshop di Pondok Pesantren Al Munawarrah Pekanbaru. Siswa-siswi mempelajari simulasi robot untuk dapat memahami dan mengetahui mekanisme dasar dari robot. Dalam simulasi ini, dipelajari pemrograman dasar dalam menggerakan robot. Software simulasi robomind menampilkan halaman untuk robot untuk bergerak dan kolom untuk pemrograman robot berupa sourch coding yang digunakan untuk menggerakkan robot. Dengan software ini siswa-siswa di pondok dapat memahami dan mengetahui dalam menjalankan atau menggunakannya serta mengerti pemrograman untuk robot.
\end{abstract}

Kata Kunci: Software Robomind, Robot, Siswa-siswi

\section{ABSTRACT}

Robomind is a free software that can learn simulations of artificial intelligence systems such as robots. Robomind software was created as a learning in the field of robot technology. With this Robomind can be learned basic programming techniques in knowing the working process of a robot. Robomind software can be used in the world of education as a learning for beginners about robot simulation for junior high and high school students or equivalent. In the face of the industrial revolution 4.0 technological developments will continue to develop, then this technological life can not be denied. In order for these students to face the technological developments that have entered the industrial revolution 4.0, must be able to know the technology by learning and understanding the development of each update. One of the technological developments in the field of Artificial Intelligence or artificial intelligence. Robomind software is applied in the learning process to students in the form of a workshop at Al Munawarrah Islamic Boarding School Pekanbaru. Students study robot simulation to understand and know the basic mechanics of robots. In this simulation, basic programming in moving the robot is learned. The robomind simulation software displays a page for the robot to move and a column for programming the robot in the form of source coding that is used to move the robot. With this software, students at Pondok can understand and know how to run or use it and understand programming for robots.

Keyword: Robomind software, robot, student

\section{PENDAHULUAN}

Latar Belakang

Perkembangan teknologi setiap tahun melakukan pembaharuan sesuai perkembangan zaman saat era tersebut. Salah satunya perkembangan teknologi di bidang ilmu artificial Intelligence atau dapat dikatakan kecerdasan buatan. Saat ini bagi generasi muda sangat diperlukan mengetahui perkembangan teknologi. Agar generasi muda saat ini dapat mengetahui dan memahami perkembangan teknologi. Salah satu perkembangan ilmu kecerdasan buatan adalah robot atau manusia tiruan. Robot berasal dari bahasa Cheko yaitu "robota" yang berarti alat atau sistem yang bekerja tidak mengenal lelah atau bosan. Robot biasanya digunakan untuk tugas yang berat, berbahaya, pekerjaan yang berulang-ulang [6]. 
Robot merupakan peralatan elektro-mekanik atau bio-mekanik, atau gabungan peralatan yang menghasilkan gerakan otonomi maupun berdasarkan gerakan yang diperintahkan [3]. Untuk memahami dan mempelajari mekanisme sebuah robot, maka untuk pemula dapat mempelajari sebuah sebuah software yang bernama Robomind. Software (perangkat lunak) yang merupakan program yang pada dasarnya menjalankan perintah dari user [2]. Program Robomind menampilkan kolom untuk gambar robot untuk bergerak dan kolom untuk algoritma. Robomind adalah salah satu Programming Assistant Tool (PAT), berbentuk simulasi program yang khusus digunakan untuk meningkatkan kemampuan siswa dan memahami konsep pemrograman serta meningkatkan kemampuan berpikir logis dan pemecahan masalah. [5]. Robot pada program Robomind menyediakan perintah untuk mengatur pergerakan robot yaitu forward, backward, left, right, north, south, west, east selain itu perintah untuk mengasir wilayah dengan warna berupa paintwhite, paintblack, stoppainting dan juga perintah mengambil objek dan meletakkan objek seperti pickup, putdown, dan eatup serta lebih banyak lagi perintah lainnya pada Robomind [4]. Pergerakkan robotnya diatur perlangkah dikarenakan halaman untuk robotnya bergerak dalam bentuk ubin.

Software Robomind ini, akan di implementasi dalam bentuk pengabdian bagi penulis berupa workshop atau pelatihan. Workshop Robomind ini, dilakukan di Pondok Pesantren Al Munawarrah Pekanbaru. Di Pondok Pesantren Al Munawarrah Pekanbaru bagi siswa-siswinya yang tingkat akhir atau dikatakan sudah menyelesaikan belajar, mereka diberikan belajar setahun atau mengabdi setahun. Dengan pengetahuan dasar pemrograman robot pada software Robomind, setidaknya siswa-siswi dapat memahami prinsip kerja robot dan pemogramannya serta mampu memprogram menggunakan program secara manual dan otomatis Robomind agar robot dapat bergerak dari satu tempat ketempat yang lain secara simulasi [1]. Tujuan pelaksanaan pengabdian ini dengan memberikan pelatihan kepada santriwan/santriwati menggunakan software Robomind, yaitu memberikan pemahaman mengenai algoritma dasar pemrograman robot dengan menggunakan software Robomind dengan menjelaskan prinsip kerja robot dan mengimplementasikan simulasi Robomind. Dengan melaksanakan tujuan pengabdian, maka pengabdian akan memberikan manfaat bagi santriwan/santriwati dengan mereka mengerti dan memahami algoritma dasar pemrograman robot dari simulasi robot dengan Robomind.

\section{METODE PELAKSANAAN}

Pelaksanaan pengaabdian kepada masyarakat disajikan dalam bentuk pelatihan atau workshop mengenal algoritma dasar dari pemrograman robot dengan menerapkan simulasi robot menggunakan software Robomind. Berikut kerangka kerja pelaksanaan pengabdian kepada masyarakat pada gambar 1 sebagai berikut : 


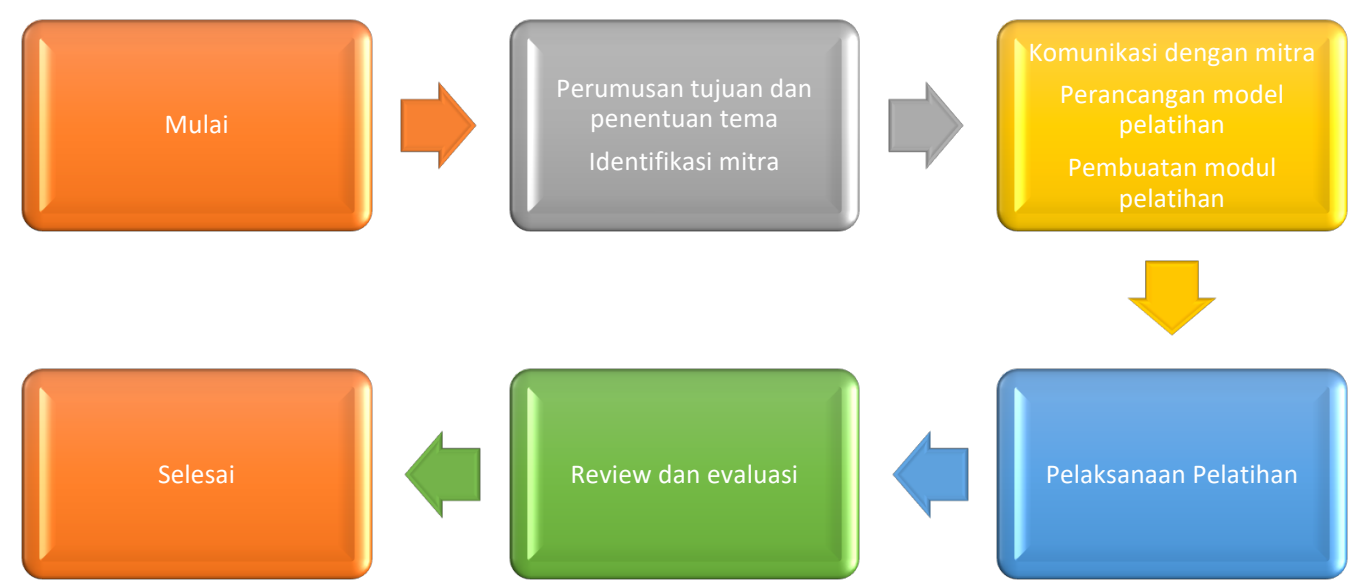

Gambar 1. Kerangka Kerja Kegiatan Pengabdian

Metodologi pelaksanaan kegiatan pengabdian dilakukan dengan beberapa tahapan sebagai berikut:

1. Tahapan perumusan tujuan dan penentuan tema, dilakukan beberapa kali pertemuan untuk mendiskusikan permasalahan mitra, tujuan kegiatan pengabdian, menentukan bentuk kegiatan serta penentuan bentuk luaran.

2. Tahapan komunikasi dengan mitra untuk mendiskusikan format kegiatan dan tujuan kegiatan, setelah itu membuat perancangan model pelatihan yang disesuaikan dengan karakteristik mitra. Hasil dari tahapan ini adalah modul pelatihan yang digunakan oleh peserta pelatihan.

3. Tahapan pelaksanaan pelatihan ini dimulai dengan teori (menjelaskan materi) dan dilanjutkan dengan bagian praktikum masing-masing peserta. Dan juga disertai dengan daftar hadir dari peserta pelatihan.

4. Evaluasi dan Review merupakan tahapan memberikan evaluasi kepada peserta dalam bentuk latihan dan sesi diskusi apabila ada pertanyaan dari peserta dan mereview latihan yang diberikan.

\section{HASIL}

Hasil dari kegiatan ini diharapkan seluruh peserta dapat mengetahui dan memahami Bahasa pemrograman dasar dari pemrograman robot dengan tools Robomind. Materi yang diberikan saat pelatihan:

1. Pengetahuan dasar mengenai robot

2. Pengenalan simulasi robot berupa software Robomind

3. Latihan menggunakan Robomind

Software RoboMind adalah pemrograman sederhana untuk pendidikan menggunakan bahasa scripting sendiri dan memungkinkan pemula untuk dapat mengetahui dasar-dasar ilmu komputer dengan pemrograman robot. Selain memperkenalkan teknik pemrograman umum, juga bertujuan menawarkan wawasan dalam robotika dan kecerdasan buatan, tersedia sebagai aplikasi yang berdiri sendiri untuk Windows, Linux dan Mac OSX (Gunardi, 2020).

Ini pertama kali dirilis pada tahun 2005 dan pada awalnya dikembangkan oleh Arvid Halma, seorang mahasiswa dari University of Amsterdam pada waktu itu. Sejak 2011 diterbitkan 
oleh Kitchen Penelitian. Software ini cocok untuk yang baru belajar pemrograman, karena dalam software ini, kita bisa mengatur sendiri langkah - per langkah kita untuk mengatur gerakan robot, dalam hal ini melatih kemampuan kita dalam penguasaan algoritma dan logika. Selain itu dalam ini terdapat pula beberapa struktur pemrograman seperti halnya bahasa pemrograman pada umumnya, seperti bentuk IF, LOOPING, dan PROCEDURE (Gunardi, 2020).

Pemrograman Robomind sangat interaktif dikarenakan Robomind menggunakan simulasi pemrograman robot dengan kecerdasan buatan. Keunggulannya sebagai berikut:

1. Bahasa pemrograman robot yang sederahana.

2. Mudah dipahami bagi pemula.

3. Tidak mengganggu sistem komputer.

4. Bersifat freeware

5. Dapat dijalankan di sistem operasi Windows, Linux, dan Mac OSX.

6. Simulasi robot seperti sebuah game.

Untuk melihat pengaruh dari kegiatan ini, dilakukanlah monitoring dan evaluasi kepada semua peserta setelah kegiatan dilakukan. Evaluasi dilakukan beberapa praktikum sebagai berikut :

1. Membuat latihan dengan robot melakukan mengecat map dengan mengimplementasikan nama masing-masing.

Contoh:

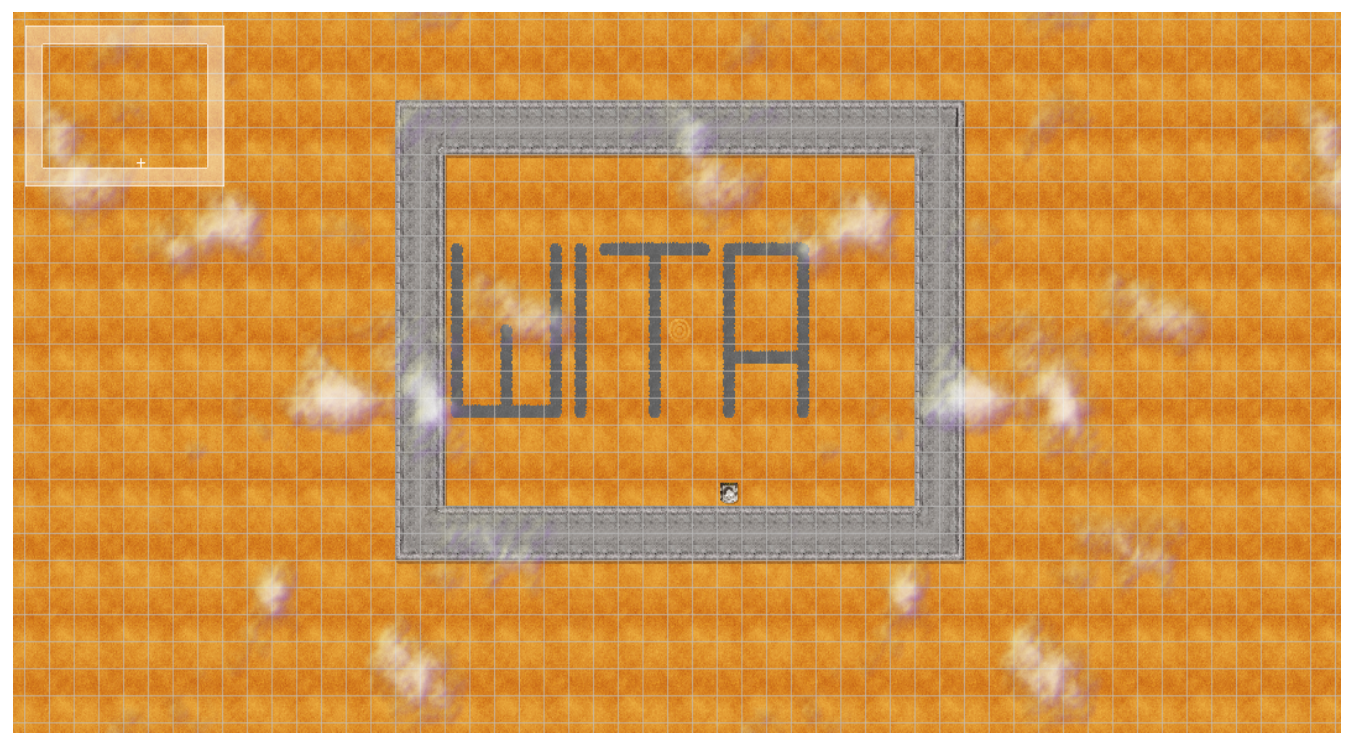

Gambar 2. Mengecat Area dengan Nama-Nama Maisng-Masing

2. Memberikan tes ke setiap peserta sesuai dari keinginan atau kemampuan peserta menggunakan map jenis OpenArea.

\section{Dokumentasi Kegiatan}

Berikut pada gambar-gambar adalah dokumentasi kegiatan yang telah dilaksanakan : 


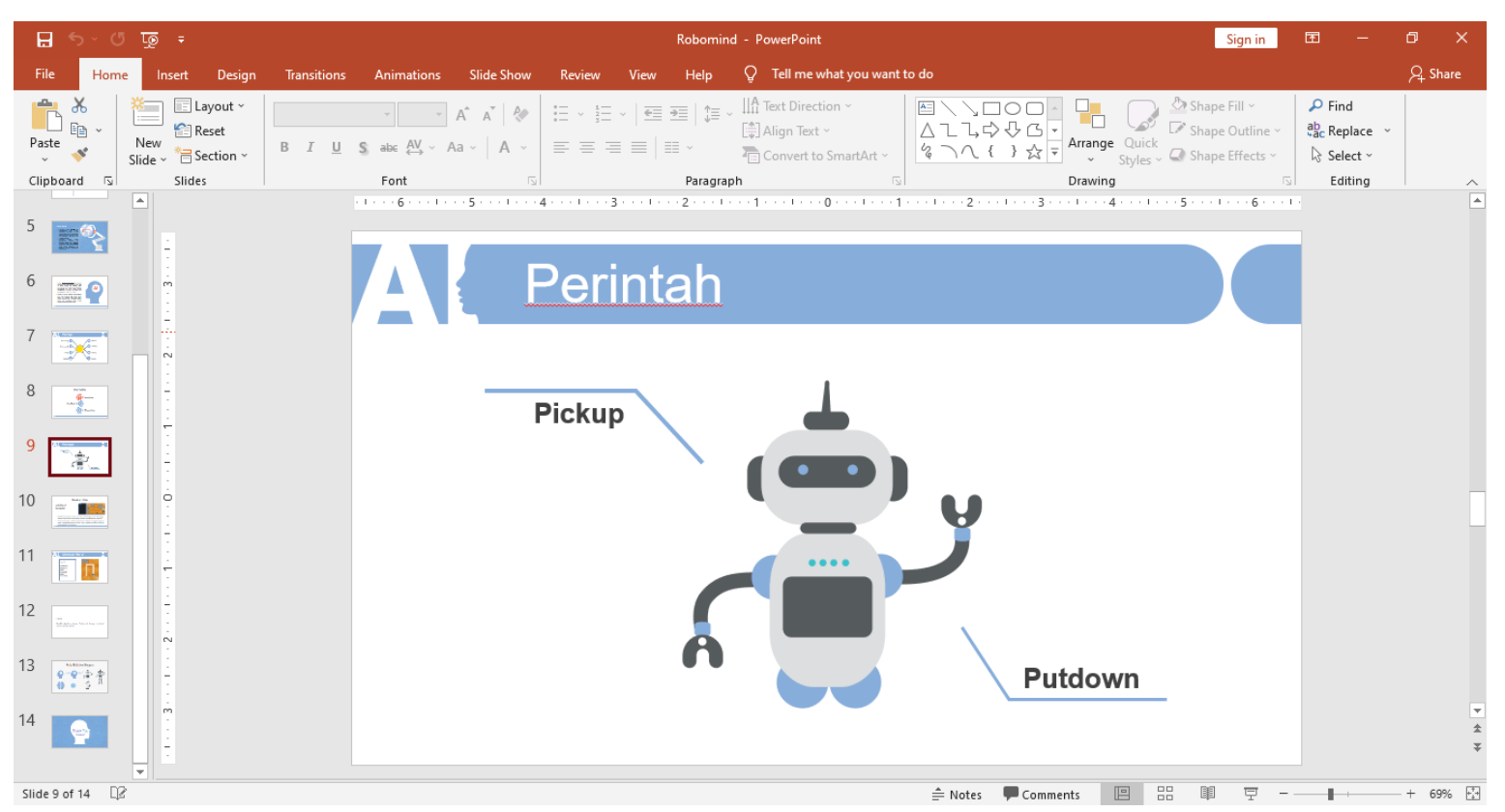

Gambar 3. Modul Pelatihan
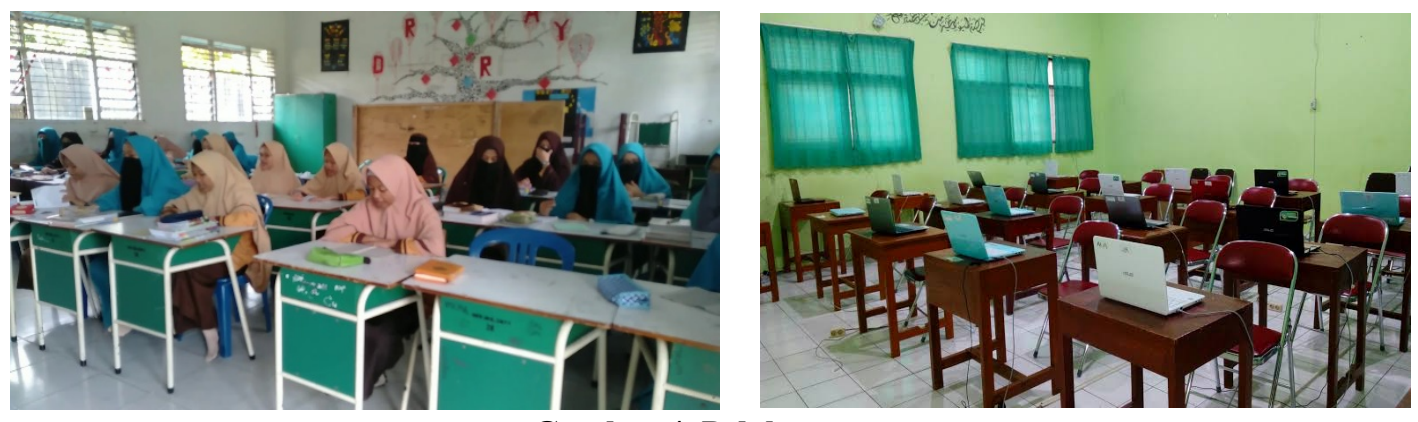

Gambar 4. Pelaksanaan

\section{KESIMPULAN}

Kegiatan pengabdian yang telah dilakukan kepada peserta santriwan/santriwati Pondok Pesantren Al Munawwarah dalam mempraktikumkan pemrograman simulasi robot menggunakan software roboming memberikan dampak yang luar biasa. Berdasarkan hasil praktikum dan evaluasi (test) yang telah dilakukan kepada peserta menyampaikan bahwa:

1. Program pemberian pelatihan menggunakan tools Robomind kepada santriwan/santriwati sangat berdampak baik dengan mereka yang sangat bersemangat dalam memahami programing dasar robot dan mempraktekkannya di perangkat masing-masing.

2. Materi yang diberikan sesuai yang diinginkan peserta dan peserta memperoleh wawasan tambahan mengenai pemrograman dasar dari robot menggunakan tools Robomind.

3. Materi seperti ini dapat memicu mereka untuk lebih semangat mempelajari lagi Bahasa program robot lebih lanjut dan bisa dapat memotivasi mereka dengan dapat menciptakan teknologi ke depannya.

\section{DAFTAR PUSTAKA}

[1] Gunardi, Y., Budiyanto, S., Ibnu Hajar, M. H., Andika, J., \& Supegina, F. (2020). 
Pengenalan Teknologi Robot Menggunakan Software Robomind Untuk Remaja Masjid Al Hikmah Taman Aries Jakarta Barat. Minda Baharu, Vol. 4(No. 2), 115-121.

[2] Kadir, A., Triwahyuni, T. (2013). Pengantar Teknologi Informasi (Revisi; H. Dewi, ed). Yogyakarta: Penerbit Andi.

[3] Umi Kalsum, T., Aulia Trianggana, D., \& Hermawansyah. (2013). Robot Pendeteksi Api Menggunakan Bahasa Pemrograman Basic Stamp. Jurnal Media Infotama, Vol. 9(No. 1), 21.

[4] Robomind. Basic Instructions. https://www.robomind.net/en/docBasicInstructions.htm.

[5] Sabril, A., \& Mukhlisah Abdal, N. (2020). Perbandingan Waktu Tempuh Mobile Robot Dalam Arena Labirin Dengan Algoritma Tangan Kiri Dan Algoritma Tangan Kanan. Jurnal Media Elektrik, Vo. 17(No. 3), 3-7.

[6] Yudanto, S. H. (2013). Belajar Pemrograman Dasar Robotik dengan Bantuan RoboMind. Retrieved from http://www.pusatgratis.com/software/belajar-pemrograman-dasarrobotik-dengan-bantuan-robomind.html. 